\title{
Three cases of acute porphyria, presenting with severe hyponatremia
}

\begin{abstract}
Porphyrias are a group of rare metabolic diseases that result from enzymatic defects of porphyrins metabolism and heme synthesis. Accumulation of porphyrins and their precursors present with neuro-visceral symptoms and/or skin lesions. Acute porphyrias may have variety of manifestations; most common of them are abdominal pain and central nervous system disturbances, hyponatremia is highly characteristic for acute intermittent porphyria and is usually attributed to syndrome of inappropriate secretion of antidiuretic hormone (SIADH). We present here three cases of acute porphyria, primary diagnosed in ICU by nephrologist, invited for evaluation and treatment of severe hyponatremia and discuss causes of hyponatremia, differentiating between SIADH and cerebral salt wasting (CSW) syndrome.
\end{abstract}

Volume 2 Issue 2 - 2015

\section{Elena $\vee$ Zakharova}

Nephrology, Moscow State University of Medicine and Dentistry, Russia

Correspondence: Elena Zakharova, State University of Medicine and Dentistry, City Clinical Hospital n.a. S.P. Botkin, I I 5284, 2-nd Botkinsky proezd, 5, Moscow, Russia, Tel +7 499 728 8291, +7 495945 1756, Email helena.zakharova@gmail.com

Received: February 02, 2015 | Published: April 0I, 2015

Keywords: acute porphyria, clinical, electrolyte imbalance

Abbreviations: ALA, amino levulonic acid; AlAT, alanine amino transferase; AsAT, asparagine amino transferase; BP, blood pressure; $\mathrm{Ca}$, calcium; $\mathrm{CK}$, creatine phosphokinase; $\mathrm{Cl}$, chloride; CSW, cerebral salt wasting; CT, computer tomography; ECG, electrocardiogram; ECHO-CG, echocardiography; Hb, hemoglobin; HPF, high power field; HR, heart rate; K, potassium; LDH, lactate dehydrogenase; LP, lumbar punction; Na, sodium; NSAID's, nonsteroid anti-inflammatory drugs; O2 Sat, oxygen saturation; PBG, porphobilinogen; Plt, platelets; Posm, plasma osmolality; RBC, red blood cells; $\mathrm{RR}$, respiratory rate; SIADH, syndrome of inappropriate secretion of antidiuretic hormone; SG, specific gravity; TB, total bilirubin; TBC, total blood count; TP, total protein; UTI, urinary tract infection; WBC, white blood cells

\section{Introduction}

The Porphyrias are a group of rare metabolic diseases that result from defects (genetic or, rarely, acquired) of enzymes needed at various steps of heme synthesis. As precursors of heme are porphyrins, deficiencies in any of enzymes, involved in their metabolism, may lead to the accumulation of porphyrins, presenting with distinct clinical syndromes- acute or chronic. Porphyrias are also classified into those predominantly involving the skin, those manifesting as disorders of the liver/nervous system, and a combination involving all 3 entities. Clinical manifestations depend on the particular enzymatic defects -if the defects are in the initial steps of the metabolic cascade, neurotoxic early metabolic intermediate products (i.e. amino Levulonic acid and Porphobilinogen) accumulate, resulting with attacks of neurologic dysfunction; if the defects are in the final steps, porphyrin accumulate in the skin causing photosensitivity. The acute porphyrias are characterized by periodic acute attacks of neurovisceral symptoms. This group include acute intermittent porphyria, the Doss porphyria, hereditary coproporphyria, and variegate porphyria. The chronic porphyrias (congenital erythropoietic porphyria, erythropoietic porphyria, and porphyria cutanea tarda) are dermatologic diseases that may or may not involve the liver and nervous system and do not present with acute attacks. ${ }^{1-3}$
Acute porphyria clinical presentation may include:

I. Abdominal pain

II. Constipation/diarrhoea

III. Nausea/vomiting

IV. Arterial hypertension/tachycardia

V. Fever

VI. Sweating

VII. Muscle weakness

VIII. Tetra paresis

IX. Respiratory paralysis

X. Limb pain

XI. Motor neuropathy

XII. Paresthesias/dysesthesias, numbness

XIII. Cranial nerve involvement/blindness

XIV. Tremor

XV. Seizures

XVI. Urinary retention/incontinence, dysuria

XVII. Aphasia/apraxia

XVIII. Psychosis

XIX. Anxiety/restlessness

$\mathrm{XX}$. Agitation

XXI. Confusion/coma

XXII. Depression/insomnia

XXIII. Skin rush 
XXIV. Rhabdomyolysis

XXV. Red/brown urine

XXVI. Elevated WBC count

\section{Hyponatremia}

Acute intermittent porphyria is the most common and the most severe form of the inherited hepatic porphyrias, affecting mainly young women. Provoking factors are known to be alcohol ingestion, infection, surgical procedure, variety of drugs, low-carbohydrate diet or fasting and menstruation. ${ }^{4-11}$ We present three cases of newly diagnosed acute porphyria, presenting with severe hyponatremia in ICU.

\section{Case I}

Nephrologist was invited to ICU to consult the patient with hyponatremia ( $\mathrm{Na} 103 \mathrm{mmol} / \mathrm{l})$. Caucasian lady 29years old, day 6 in the hospital, day 2 in ICU.

\section{Physical examination}

Erythematosus face rash, lips red boarder bright, no edema, skin and mucous dry. Coma, motor excitement, adequate pain reaction, lack of swelling, normal cough reflex, widened pupils with normal photo reactivity. Body temperature $37.0^{\circ} \mathrm{C}$, spontaneous respiration, RR 25 per minute, HR140 per minute, BP160/85 mm Hg. Heart and lung unremarkable, abdomen soft, non-tender. Stool after enema, normally colored, urination via ureteral catheter, urine colored reddish-brown, urine output $4800 \mathrm{ml} /$ day.

\section{Workup}

HB $15.6 \mathrm{~g} / \mathrm{dl}$, WBC $12.9 \times 10 * 6 / \mathrm{mcl}$, Plt127×10*6/mcl, TP $6.2 \mathrm{~g} /$ $\mathrm{dl}$, TB $20 \mathrm{mcmol} / 1$, creatinine $66 \mathrm{mcmol} / 1$, urea $4,9 \mathrm{mmol} / 1$, uric acid 189mcmol/l, AsAT 137U/l, AlAT66 U/l, amylase 218U/1, CK 25899U/1, LDH $650 \mathrm{U} / 1$, K 2.8mmol/1, Na 103mmol/1, Ca+ $0.97 \mathrm{mmol} / 1, \mathrm{Cl} 73 \mathrm{mmol} / 1$, Posm $214 \mathrm{mosm} / \mathrm{kg}$, pH 7.55, bicarbonate $25.3 \mathrm{mmol} / 1$, O2sat $91 \%$ at room air.

\section{LP} $15 / 3$

Liquor colorless, transparent, protein $1.1 \mathrm{~g} / 1$, neutrophil cytosis

\section{Urinalysis}

Protein 0.5g/1, glucose-abs, WBC 3-4, RBC 1-2 HPF, bilirubin ${ }^{++}$, urobilin $^{+++}$.

\section{Previous medical history}

Unremarkable-nothing but normal pregnancy 5years ago. She was known to have respiratory symptoms, chill, fever $\left(38.6^{\circ} \mathrm{C}\right)$ and myalgia6days before admission, and taking paracetamol and antibiotics. In two days respiratory symptoms resolved, but she experienced abdominal pain, vomiting, constipation, and noticed dark urine (Figure 1).

\section{Clinical course}

3days later, with the same complains she was seen in ER of our hospital. Physical examination did not show anything significant. Workup, including standard labs, ECG, ultrasound, chest and abdomen plain X-ray, radio contrast kidney X-ray and laparoscopy found nothing but "reddish-brown" urine (protein $0.033 \mathrm{~g} / \mathrm{l}$, RBC $70-80 \mathrm{hpf})$, mild hyponatremia (133mmol/1), and sinus tachycardia. She was diagnosed with UTI, referred to urology unit and started with NSAID's, antiemetic's, spasmolytics, Ringer solution, cephalosporin's, antifungal and omeprazole.

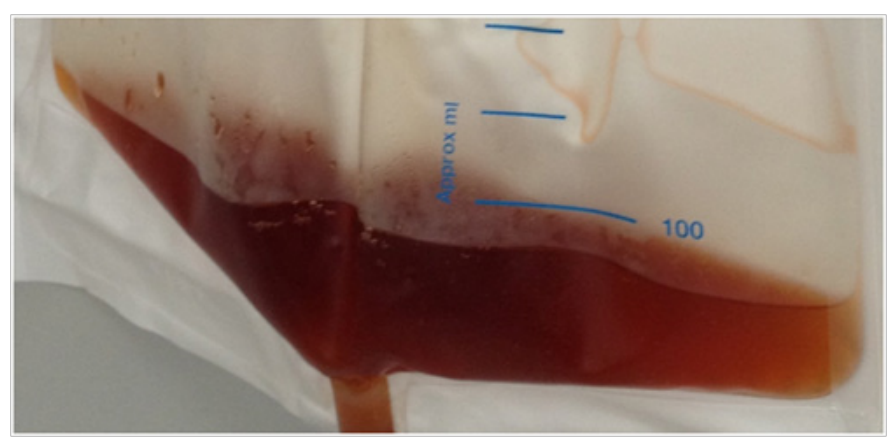

Figure I Case I-dark urine.

Day 3 in the hospital fever resolved, but she complained for dysuria and severe back pain, which were interpreted as a consequence of her regular menses, Novocain was added to her treatment. Day 5 she was found depressive, and started with amitriptyline, the same night she developed seizures (treated with carbamazepine and diazepam), and coma. CT showed brain edema, and she was transferred to ICU and continued with diazepam, carbamazepine, omeprazole, cephalosporins and normal saline; potassium chloride and magnesium were added.

\section{Diagnosis and follow-up}

Day 6 (day 2 in the ICU) her neurologic status was unchanged, hemodynamics-stable, but respiratory distress worsened. Given skin lesions, abdomen pain and constipation, seizures, coma, dark urine, and hyponatremia-nephrologist suspected acute porphyria. High CK and LDH were attributed to rhabdomyolysis. Additional workup, including urine Ehrlich test for porphyrins was recommended, and it was advised to discontinue magnesium, antibiotic's and anticonvulsant's, and infuse $\mathrm{NaCl} 3 \%$ solution $1-2 \mathrm{ml} / \mathrm{kg} /$ hour under serum sodium control, targeting sodium not higher than $115-116 \mathrm{mmol} / \mathrm{l}$ at the end of first day.

Day 8 (day 4in ICU) patient's condition improved. Spontaneous respiration, conscious, but confused, BP 140/80 mmHg, HR120 per minute. Plasma Na-122mmol/1, urine output $2600 \mathrm{ml} / 24$ hours, urine still reddish-brown, and Ehrlich test-positive. Diagnosis of acute porphyria with first clinical manifestation after viral infection, menstruation, and NSAIDS, antibiotics and sedatives usage was confirmed. Day 10 (day 6 in ICU) she was stable, slightly confused, BP 135/85 mm Hg, HR 110 per minute. Plasma Na $129 \mathrm{mmol} / \mathrm{l}, \mathrm{K}$ $4.1 \mathrm{mmol} / 1, \mathrm{Ca}^{++} 1.28 \mathrm{mmol} / 1, \mathrm{Cl} 104 \mathrm{mmol} / 1, \mathrm{pH} 7.38$. Patient was transferred to reference centre for Porphyrias.

\section{Case 2}

Nephrologist was invited to ICU to consult the patient with hyponatremia (serum Na 114mmol/1). Caucasian lady 30years old, day 10 in the hospital, day 2 in ICU.

\section{Main complains}

Weakness, pain in her neck, back and lower extremities and lower extremities numbness. 


\section{Physical examination}

Lips red boarder bright, erythematous rush on her face, neck and upper extremities (Figure 2), no edema, skin and mucous dry. Conscious, slightly confused, no focal signs. Body temperature $37.2^{\circ} \mathrm{C}$, spontaneous respiration, RR 20per minute, HR78per minute, BP150/80mm Hg. Heart and lung unremarkable, abdomen soft, nontender. No stool. Spontaneous urination with red urine, urine output was $2500 \mathrm{ml} /$ day.

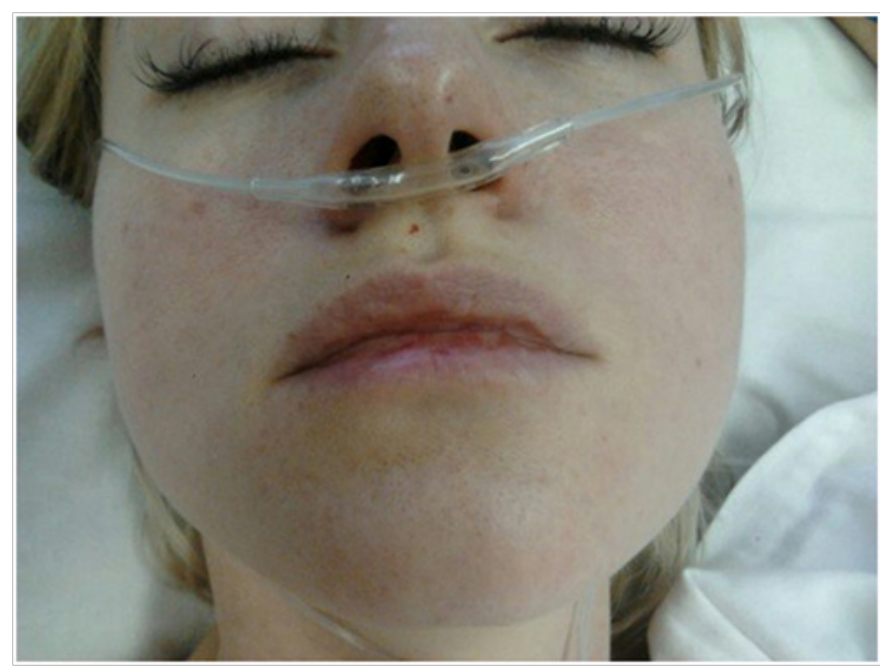

Figure 2 Case 2-skin rush.

\section{Workup}

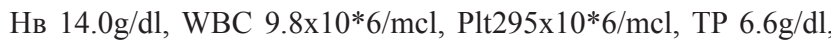
albumin $3.6 \mathrm{~g} / \mathrm{dl}$, TB $25 \mathrm{mcmol} / 1$, creatinine $72 \mathrm{mcmol} / 1$, urea $2,0 \mathrm{mmol} / 1$, AsAT53U/1, AlAT27 U/1, amylase117U/1, CK1324U/1, LDH257U/1, K2.3mmol/1, Na $114 \mathrm{mmol} / 1, \mathrm{Cl} 84 \mathrm{mmol} / 1$, Posm $241 \mathrm{mosm} / \mathrm{kg}, \mathrm{pH}$ 7.56 , bicarbonate $30.6 \mathrm{mmol} / 1, \mathrm{O} 2 \mathrm{sat} 100 \%$ at room air.

\section{Urinalysis}

Protein $0.7 \mathrm{~g} / \mathrm{l}$, bilirubin $34 \mathrm{mmol} / 1$, urobilin $50 \mathrm{mmol} / 1$, WBC, RBC - 0-1 hpf, urine osmolality $316 \mathrm{mosm} / \mathrm{kg}$.

\section{Previous medical history}

2 normal pregnancies 7 and 5years ago. 9 month before current episode, after taking vermicides (together with her kids who had seat worms), she developed severe abdominal pain and pain in lower extremities and was admitted to local hospital. She got laparotomy, which did not show any surgical disease. 3 months later she had another episode of abdominal pain, recognised as adhesive obstruction and resolved without surgery.

At the day of admission she developed abdominal pain and 6hours later was admitted to surgery unit of our hospital, suspected for appendicitis. Her vital signs were otherwise normal, abdomen soft and non-tender, slightly painful in epigastrium and right flank.

\section{Clinical course}

Normal TBC and blood chemistry but plasma $\mathrm{Na} 133 \mathrm{mmol} / 1$, and normal urinalysis. ECG showed sinus tachycardia. Abdomen and pelvic ultrasound and plain abdomen X-ray were normal, small bowel follow through showed ileocecal barium retention; she was diagnosed with adhesive obstruction and treated with normal saline, Ringer solution and spasmolytics.
Day 3 of hospital stay she still had diffuse abdominal pain and complained for pain in lower extremities, her vital signs, stool and urination were normal. TBC was normal with $\mathrm{Hb} 16.0 \mathrm{~g} / \mathrm{dl}$, blood chemistry found TB $28 \mathrm{mcmol} / 1$, creatinine $84 \mathrm{mcmol} / 1$, urea 2.2mmol/1, AsAT $66 \mathrm{U} / 1, \mathrm{Na} 130 \mathrm{mmol} / 1, \mathrm{~K} 4.2 \mathrm{mmol} / 1, \mathrm{Cl} 90 \mathrm{mmol} / 1$. Urinalysis: SG 1015, protein absent, bilirubin $8.5 \mathrm{mmol} / 1$, gastroscopy revealed reflux-gastritis, colonoscopy showed only dolychosigmoid. She was continued with normal saline, Ringer solution and spasmolytics, NSAID's were added.

Day 7 of hospital stay she complained skin rush and developed agitation, neurologist did not find any focal signs and diagnosed neurotic reactions, sulpiride was added. Dermatologist diagnosed toxicodermia and recommended to continue crystalloid infusions. Day 9 of hospital stay her condition worsened, she complained of pain in her neck, back and lower extremities, found to be hypovolemic and confused, referred to ICU and continued with normal saline, Ringer solution, omeprazole and NSAID's; cephalosporin's, amino glycoside's, calcium-channel blockers, beta-blockers, ACE-inhibitors, heparin and diazepam were added.

\section{Diagnosis and follow-up}

Day 10 (day 2 in ICU) her condition did not changed. Nephrologist, basing on 3 episodes of abdominal pain, laparotomy with uncertain diagnosis 9 months ago, skin rush, neck, back and low extremities pain, arterial hypertension and tachycardia, agitation, numbness, red urine and hyponatremia suspected acute porphyria. It was advised to perform urine Ehrlich test for porphyrins, discontinue antibiotics, heparin, diazepam, NSAID's, anti-hypertensive's, and infuse Glucose $40 \% 1000 \mathrm{ml} /$ day and $\mathrm{NaCl} 3 \%$ solution $1-2 \mathrm{ml} / \mathrm{kg}$ /hour under serum sodium control, targeting sodium not higher than $125 \mathrm{mmol} / 1$ at the end of first day.

Day 12 of hospital stay (day 4 in ICU) patient's condition improved - conscious, alert, no focal signs, mild pain and numbness in lower extremities. Vital signs normal, urine output $2000 \mathrm{ml} /$ day. Normal stool. Plasma Na 129mmol/1, K 4.1mmol/1, CK 346 U/1. Ehrlich test positive. Diagnosis of acute porphyria was confirmed and patient was transferred to reference centre for Porphyrias.

\section{Case 3}

Nephrologist was invited to ICU to consult the patient with hyponatremia (serum Na $112 \mathrm{mmol} / \mathrm{l}$ ). Caucasian lady 39years old, day 4 in the hospital, day 2 in ICU. Sopor, no focal signs.

\section{Physical examination}

Erythematosus skin rush (Figure 3) and hyper pigmentation on upper extremities, no edema, skin and mucous dry. Body temperature $36.6^{\circ} \mathrm{C}$, spontaneous respiration, RR 22per minute, HR 80 per minute, BP135/80mm Hg. Lung and heart unremarkable, abdomen soft, not tender. No stool, urination via ureteral catheter, urine colored dark brown, and urine output $4300 \mathrm{ml} /$ day.

\section{Workup}

HB $13.0 \mathrm{~g} / \mathrm{dl}$, WBC $6.6 \times 10 * 6 / \mathrm{mcl}$, Plt $307 \times 10 * 6 / \mathrm{mcl}$, TP $6.5 \mathrm{~g} /$ $\mathrm{dl}$, TB $23 \mathrm{mcmol} / 1$, albumin $3.5 \mathrm{~g} / \mathrm{dl}$, creatinine $81 \mathrm{mcmol} / 1$, urea 3,8mmol/1, AsAT 236U/1, AlAT 81U/1, amylase 102U/1, CK 9570U/1, LDH $379 \mathrm{U} / \mathrm{l}, \mathrm{K} 2.9 \mathrm{mmol} / \mathrm{l}$, Na $112 \mathrm{mmol} / \mathrm{l}, \mathrm{Cl} 85 \mathrm{mmol} / 1$, Posm $231 \mathrm{mosm} / \mathrm{kg}$, pH 7.49 , bicarbonate $20.4 \mathrm{mmol} / 1, \mathrm{O}_{2}$ sat $100 \%$ at room air. 


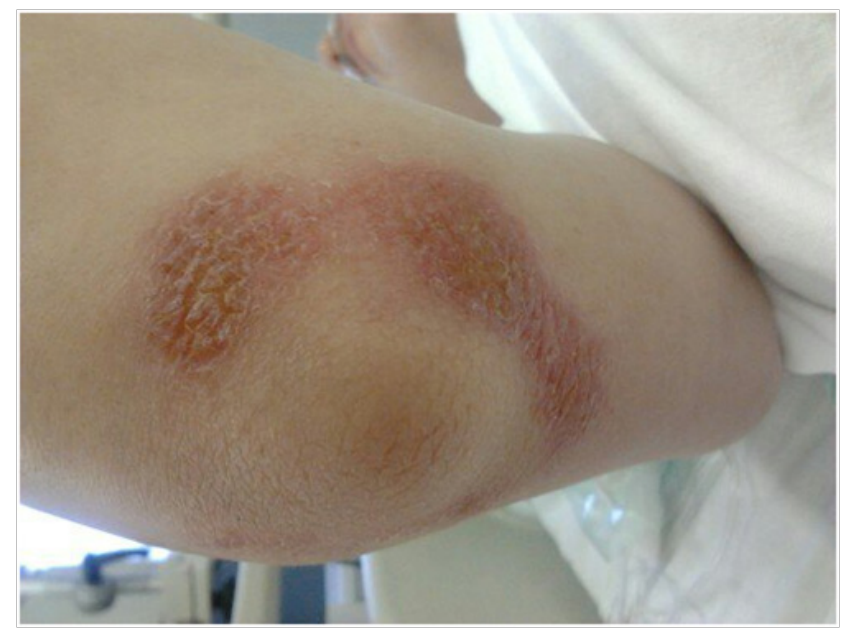

Figure 3 Case 2-skin rush.

\section{Urinalysis}

SG 1015, protein abs, bilirubin 34mmol/1, urobilin 34mmol/1, WBC, RBC-absent. ECG showed sinus tachycardia and ST elevation in 2-nd standard lead, ECHO-CG revealed left ventricular dilatation and anteroseptal hypo kinesis with ejection fraction $42 \%$.

\section{Previous medical history}

Normal pregnancy 14years ago, since that time she was taking oral contraceptives. 3years ago she had anepisode of abdominal pain; laparotomy did not show any surgical disease. 2 weeks before current admission she developed abdominal pain, was admitted to the surgery unit our hospital, complaining for constipation, and diagnosed with abdominal colic. Her vital signs were otherwise normal, abdomen, slightly painful but soft and non-tender. Workup showed normal TBC, blood chemistry revealed total bilirubin 40mmol/1, AsAT 166U/1, AlAT $98 \mathrm{U} / 1$, cholesterol $8.3 \mathrm{mmol} / 1$, K 3.9mmol/1, Na 106mmol/1, other test were normal. Urinalysis was not performed. ECG, abdomen and kidney ultrasound, chest and abdomen plain X-ray, abdomen CT and colonoscopy were unremarkable. She was seen by neurologist and diagnosed with asthenia. She received spasmolytics and laxative's, her condition improved and she was discharged on the 9-th day of hospital stay. Her blood chemistry abnormalities were not interpreted.

2days after discharge she was seen in ER of our hospital for severe abdominal pain, nausea, vomiting and dark urine. Her vital signs normal, abdomen soft and non-tender.

\section{Clinical course}

$\mathrm{Hb} 12.9 \mathrm{~g} / \mathrm{dl}$, WBC $5.0 \times 10 * 6 / \mathrm{mcl}$, Plt $230 \times 10 * 6 / \mathrm{mcl}$, TB9 $\mathrm{mcmol} / 1$, creatinine $71 \mathrm{mcmol} / 1$, urea $2,6 \mathrm{mmol} / 1$, AsAT $84 \mathrm{U} / \mathrm{l}$, AlAT $57 \mathrm{U} / 1$, amylase $157 \mathrm{U} / 1, \mathrm{~K} 4.8 \mathrm{mmol} / 1, \mathrm{Na} 129 \mathrm{mmol} / 1, \mathrm{Ca}^{++} 1.1 \mathrm{mmol} / \mathrm{l}$, Cl 100mmol/1; urinalysis: SG 1010, protein-abs, bilirubin $8.5 \mathrm{mmol} / 1$, WBC, RBS-abs. Plain chest, abdomen and kidneys X-ray, abdomen and kidneys ultrasound-otherwise normal but mild pancreatic hyperechogenicity. She was diagnosed with pancreatitis, referred to surgery unit and treated with normal saline, Ringer solution, NSAID's, spasmolytics, cephalosporins and omeprazole.

Day 3 of hospital stay her condition worsened-she became disoriented, with agitation and psychomotor excitement. Brain CT did not show anything significant, she was diagnosed with "toxic psychosis", referred to ICU and continued with normal saline, Ringer solution, NSAID's, cephalosporin's and omeprazole; heparin was added.

\section{Diagnosis and follow-up}

Day 4 (day 2 in ICU) her vital signs were stable, but she became soporos. Nephrologist, basing on prolonged usage of oral contraceptives, laparotomy for uncertain indications 3years ago, abdominal pain, constipation, nausea, vomiting, psychosis and hyponatremia suspected acute porphyria. It was advised to perform urine test for porphyrins, discontinue antibiotics, NSAID's and heparin, and infuse Glucose $40 \% 1000 \mathrm{ml} /$ day and $\mathrm{NaCl} 3 \%$ solution $1-2 \mathrm{ml} / \mathrm{kg} /$ hour under serum sodium control, targeting sodium not higher than $120 \mathrm{mmol} / 1$ at the end of first day.

Day 5 (day 3 in ICU) her condition improved-conscious, alert, no focal signs. Vital signs normal, urine output $6200 \mathrm{ml} /$ day. Stool after enema, normally coloured. Plasma Na $125 \mathrm{mmol} / 1$, K $4.7 \mathrm{mmol} / 1$, CK 1448 U/1, LDH 574 U/1. Urine test for porphyrins: Total porphyrins $0.29 \mathrm{mg} / \mathrm{l}, \mathrm{PBG} 81 \mathrm{mg} / \mathrm{ml}$, ALA $21 \mathrm{mg} / \mathrm{l}$. Diagnosis of acute porphyria was confirmed and patient was transferred to reference centre for Porphyrias.

\section{Discussion}

All three cases, we present here, show typical manifestations of acute porphyria with numerous abdominal and central nervous system symptoms, rhabdomyolysis, and coloured urine, and also with skin lesions in two cases. Female sex and young age, as well as trigger factors like infection, menstruation and various medications is very common in acute porphyria. Misdiagnosing, laparotomy and treatment with NSAID's, antibiotics and sedatives, which lead to the deterioration of patients condition, is also characteristic for cases of acute intermittent porphyria before proper diagnosis is made. ${ }^{12-18}$

Marked hyponatremia, which is most common electrolyte imbalance in patients with neurologic diseases, frequently complicates acute porphyrias. Its mechanism is not fully understood, but SIADH, gastrointestinal losses, infusions of hypotonic dextrose-containing fluids, nephrotoxicity, excess renal sodium excretion, and damage to the supraoptic nuclei of the hypothalamus, has been implicated in its pathogenesis. ${ }^{16,17,19-27}$

We considered SIADH, but some clinical data could not be completely understood in this setting. SIADH is volume expanded status due to increased renal water reabsorption by excessive and inappropriate AVP secretion, often seen in patients with central nervous system diseases and hyponatremia. But many of these patients, who meet the diagnostic criteria for SIADH, have a volume status incompatible with that diagnosis. The evidence of volume depletion in these patients is more consistent with the diagnosis of CSW syndrome. CSW syndrome is characterized by excess renal sodium wasting with resulting volume depression. Although, the mechanism of CSW syndrome is not fully understood, the most possible hypothesis is central amplification of natriuretic peptides, especially brain natriuretic peptide, combined with decreased sympathetic outflow due to various neurologic diseases. SIADH and CSW syndrome are two main mechanisms of hyponatremia in patients with various neurologic diseases, excluding iatrogenic causes. Distinction between SIADH and CSW syndrome may be difficult due to overlapping laboratory findings and clinical presentations, the fundamental differences between these two entities are as follows: 
SIADH is in a volume expanded status due to inappropriately secreted AVP, however, CSW syndrome is in a volume depleted status characterized by renal sodium wasting and appropriate secretion of AVP. ${ }^{28-32}$

In our three patients plasma osmolality was decreased to 214,241 and $231 \mathrm{mosm} / \mathrm{kg}$ respectively, but they all were volume depleted, with dry skin and mucosa, hemoglobin normal or as high as $16.0 \mathrm{~g} /$ $\mathrm{dl}$, and urine output increased. Only one of our three patients had vomiting, not that much prolonged, and none of them were diarrheal. Also none got hypotonic glucose-containing infusions.

\section{Conclusion}

The main cause of severe hyponatremia in our patients was excess renal sodium excretion due to CWS syndrome, and we found only one case of similar findings explained by CSW syndrome in acute intermittent porphyria on Contemporary Pediatrics site: "A wild case of abdominal pain" by Georgy B Kenny.

\section{Acknowledgements}

None.

\section{Conflict of interest}

The author declares no conflict of interest.

\section{References}

1. Champe PC, Harvey RA. Conversion of amino acids to specialized products. Biochemistry. 2nd ed. USA: Lippincott, Williams \& Wilkins; 1994. p. 260-261

2. Forbes CD, Jackson WF. Endocrine, metabolic and nutritional. Color Atlas and Text of Clinical Medicine. 2nd ed. Spain: Times Mirror International / Mosby; 1997. 349 p.

3. Canavese C, Gabrielli D, Guida C, et al. Nephrologists and porphyrias. $G$ Ital Nefrol. 2002;19(4):393-412.

4. Anderson KE, Bloomer JR, Bonkovsky HL, et al. Recommendations for the diagnosis and treatment of the acute porphyrias. Ann Intern Med 2005;142(6):439-450.

5. Tasnadi G, Bor M, Pusztai A. Treatment of acute porphyrias The importance of follow-up of patients and carriers. ORV Hetil. 2003;144(19):933-938.

6. Zimmermann M, Bonaccurso C, Valerius $\mathrm{C}$, et al. Acute intermitten porphyria. A clinical chameleon: case study of a 40-year-old female patient. Nervenarzt. 2006;77(12):1501-1505.

7. Diot E, Corcia P, Zannad N, et al. Favorable outcome of acute porphyric neuropathy after treatment with hemearginate. Rev Neurol (Paris). 2007;163(11):1100-1102.

8. Tracy JA, DyckPJ. Porphyria and its neurologic manifestations. Handb Clin Neurol. 2014;120:839-849.

9. Bylesjo I, Forsgren L, Lithner F, et al. Epidemiology and clinical characteristics of seizures in patients with acute intermittent porphyria. Epilepsia. 1996;37(3):230-235.

10. Ellencweig N, Schoenfeld N, Zemishlany Z. Acute intermittent porphyria: psychosis as the only clinical manifestation. Isr J Psychiatry Relat Sci. 2006;43(1):52-56.
11. Millward LM, Kelly P, King A, et al. Anxiety and depression in the acute porphyrias. J Inherit Metab Dis. 2005;28(6):1099-1107.

12. Watson CJ. Porphyria. In: Dock W, Snapper I, editors. Advances in Internal Medicine. USA: Year Book Publishers; 1954. p. 235-299.

13. Abel G, Palmer-Toy D. Heme synthesis and catabolism. In: Mc Clatchey KD, editor. Clinical Laboratory Medicine. 2nd ed. USA: Lippincott Williams \& Wilkins; 2002. p. 407-417.

14. Crimlisk HL. The little imitator-porphyria: a neuropsychiatric disorder. J Neurol Neurosurg Psychiatry. 1997;62(4):319-328.

15. Palmieri C, VigushinDM, Peters TJ. Managing malignant disease in patients with porphyria. QJM. 2004;97(3):115-126.

16. Suarez JI, Cohen ML, Larkin J, et al. Acute intermittent porphyria: clinicopathologic correlation. Report of a case and review of the literature. Neurology. 1997;48(6):1678-1684.

17. Shah MA, Remoroza R, Aziz K. Acute intermittent porphyria. Hospital Physician. 2002;38(2):67-71.

18. Lithner F. Could attacks of abdominal pain in cases of acute intermittent porphyria be due to intestinal angina? J Intern Med. 2000;247(3):407409.

19. Gonzalez-Arriaza HL, Bostwick JM. Acute Porphyrias: A Case Report and Review. Am J Psychiatry. 2003;160(3):450-458.

20. Thadani H, Deacon A, Peters T. Diagnosis and management of porphyria. BMJ. 2000;320(7250):1647-1651.

21. Sassa S, Kappas A. Molecular aspects of the inherited porphyrias. J Intern Med. 1998;247(2):169-178.

22. Scarlett YV, Brenner DA. Porphyrias. J Clin Gastroenterol. 1998;27(3):192-198.

23. Burgovne K, Swartz R, Ananth J. Porphyria: re examination of psychiatric implications. Psychother Psychosom. 1995;64(3-4):121130

24. Hift RJ, MeissnerPN, Kirsch RE. The clinical diagnosis, prevention and management of the hepatic porphyrias. Trop Gastroenterol. $1997 ; 18(2): 41-44$.

25. Hellman ES, Tschudy DP, Bartter PC. Abnormal electrolyte and water metabolism in acute intermittent porphyria. The transient inappropriate secretion of antidiuretic hormone. Am J Med. 1962;32:734-746.

26. Jensen NF, Fiddler DS, Striepe V. Anesthetic considerations in porphyrias. Anesth Analg. 1995;80(3):591-599.

27. Cojocaru IM, Sapira V, Socoliuc G, et al. Acute Intermittent PorphyriaDiagnostic and Treatment Traps. Rom J Intern Med. 2012;50(1):33-41.

28. Robertson GL. Regulation of arginine vasopressin in the syndrome of inappropriate antidiuresis. Am J Med. 2006;119(7 suppl 1):36-42.

29. Rabinstein AA, Wijdicks EF. Hyponatremia in critically ill neurological patients. Neurologist. 2003;9(6):290-300.

30. Palmer BF. Hyponatraemia in a neurosurgical patient: syndrome of inappropriate antidiuretic hormone secretion versus cerebral salt wasting. Nephrol Dial Transplant. 2000;15(2):262-268.

31. Berendes E, Walter M, Cullen P, et al. Secretion of brain natriuretic peptide in patients with aneurysmal subarachnoid haemorrhage. Lancet. 1997;349(9047):245-249.

32. Kim DK, Joo KW. Hyponatremia in Patients with Neurologic Disorders. Electrolytes Blood Press. 2009;7(2):51-57. 